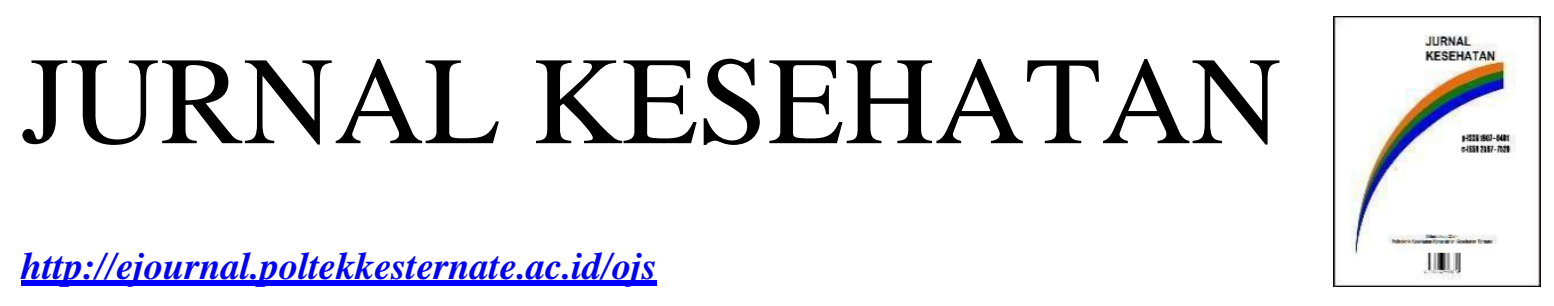

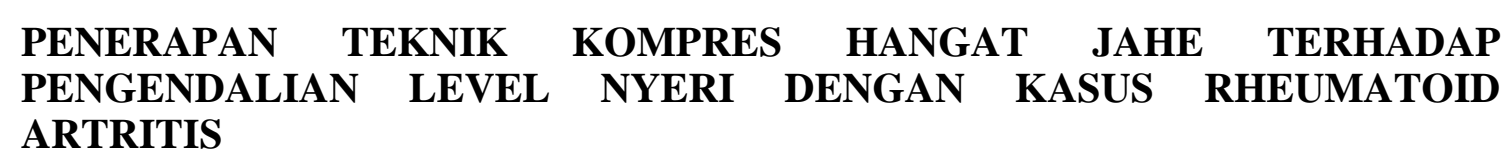
ARTRITIS

Nurfatimah $^{1},{ }^{2},{ }^{2}$
Poltekkes Kemenkes Palu Prodi Kebidanan Poso
Poltekkes Kemenkes Palu Prodi Keperawatan Poso
1 $^{2}$
Surel/Email nfatimahhh@ gmail.com

Info Artikel

Sejarah Artikel:

Diterima 25 Feb2019

Disetujui 20 Apr 2019

Di Publikasi 30 Mei

2019

Keywords:

Rheumatoid arthritis, nyeri, kompres hangat jahe
Abstrak

Rheumatoid arthritis merupakan salah satu penyakit autoimun yang berupa inflamasi arthritis pada pasien dewasa, seseorang yang menderita penyakit Rheumatoid Arthritis akan mengalami gejala berupa rasa nyeri pada bagian sinovial sendi. Berdasarkan data dari Puskesmas Mapane penderita rheumatoid arthritis tahun 2016 sebanyak 422 orang dan meningkat pada tahun 2017 menjadi 613 pasien. Penelitian ini bertujuan untuk menerapkan teknik kompres hangat terhadap pengendalian level nyeri pada asuhan keperawatan gerontik dengan kasus rheumatoid arthritis. Metode dalam penelitian ini yaitu studi kasus pada penderita rheumatoid arthritis dengan tindakan penerapan teknik kompres hangat jahe untuk mengendalikan level nyeri. Hasil terdapat pengaruh kompres hangat jahe dalam menurunkan nyeri rheumathoid arthritis dari skala 6 menjadi skala 3. Terapi kompres hangat jahe dengan 3 kali pemberian pada pagi hari selama 1 minggu dalam waktu 20 menit dapat menurunkan nyeri lutut. Kesimpulan pemberian terapi kompres hangat jahe dengan 3 kali pemberian selama 1 minggu dalam waktu 20 menit dapat menurunkan nyeri lutut. 


\begin{abstract}
Rheumatoid arthritis is an autoimmune disease in the form of inflammatory arthritis in adult patients, a person suffering from Rheumatoid Arthritis will experience symptoms of pain in the synovial joint. Based on data from the Mapane Health Center in 2016, there were 422 people with rheumatoid arthritis and it increased in 2017 to 613 patients. This study aims to apply a warm compress technique to control pain levels in gerontic nursing care with cases of rheumatoid arthritis. The method in this study is a case study in patients with rheumatoid arthritis by using a warm ginger compress technique to control the level of pain. there is the influence of warm compresses of ginger in reducing rheumatoid arthritis pain from scale 6 to 3. ginger warm compresses therapy for 3 times in the morning for 1 week in 20 minutes can reduce knee pain. Conclusion, giving warm ginger compress therapy for 3 times a week for 20 minutes can reduce knee pain.
\end{abstract}

Keywords: rheumatoid arthritis, pain, warm ginger compres

$\triangle$ Alamat korespondensi:

Poltekkes Kemenkes Ternate, Ternate - West Maluku Utara, Indonesia

ISSN 2597-7520

Email: uppmpoltekkesternate@gmail.co.id 
PENERAPAN TEKNIK KOMPRES HANGAT JAHE TERHADAP PENGENDALIAN LEVEL NYERI DENGAN KASUS RHEUMATOID ARTRITIS

PENDAHULUAN

Secara global, populasi penduduk lanjut usia terus bertambah. Saat ini, 8,5 persen orang di seluruh dunia (617 juta) berusia 65 tahun ke atas. Menurut sebuah laporan, tahun 2015 persentase ini diproyeksikan akan melonjak hingga hampir 17 persen dari populasi dunia pada tahun 2050 atau sebesar 1,6 miliar (He, Goodkind, \& Kowal, 2016).

Rheumatoid arthritis merupakan salah satu penyakit autoimun yang berupa inflamasi arthritis pada pasien dewasa, seseorang yang menderita penyakit rheumatoid arthritis akan mengalami gejala berupa rasa nyeri pada bagian sinovial sendi, sarung tendon, dan akan mengalami penebalan akibat radang yang diikuti oleh erosi tulang dan destruksi tulang disekitar sendi (Singh et al., 2016).

Di seluruh dunia, kejadian rheumatoid arthritis tahunan adalah sekitar 3 kasus per 10.000 populasi, dan angka prevalensinya sekitar 1\%, meningkat dengan bertambahnya usia dan memuncak antara usia 35 dan 50 tahun (Smith, 2018).

Prevalensi penyakit rheumatoid arthritis di Indonesia tahun 2013 (24,7\%) lebih rendah dibanding tahun 2007 (30,3\%). Di Sulawesi Tengah, prevalensi rheumatoid arthritis tahun 2013 sebesar 27\% (Departemen Kesehatan R.I, 2008) (Kementerian Kesehatan R.I, 2013).

Data yang diperoleh di Puskesmas Mapane Kecamatan Poso Pesisir dengan jumlah penderita rheumatoid arthritis Tahun 2016 sebanyak 422, meningkat pada Tahun 2017 menjadi 613 pasien. Setelah dilakukan pendataan pada 10 Kelurahan yang termasuk dalam wilayah kerja Puskesmas Mapane jumlah penderita terbanyak pada 3 bulan terakhir dari bulan Januari-Maret di Tahun 2018 terdapat 4 kelurahan yang memiliki jumlah penderita lebih dari 1 penderita yaitu Kelurahan Kasiguncu berjumlah 15 penderita, Kelurahan Bega 3 penderita dan Kelurahan Lanto Jaya 2 penderita (Puskesmas Mapane, 2017)

Kompres jahe merupakan pengobatan tradisional atau terapi alternatif untuk mengurangi nyeri rheumatoid arthritis. Kandungan enzim siklo-oksigenasi pada kompres jahe hangat dapat mengurangi

peradangan pada penderita artritis rheumatoid. Jahe juga memiliki efek farmakologis yaitu rasa panas dan pedas yang dapat meredakan rasa nyeri, kaku, dan spasme otot atau terjadinya vasodilatasi pembuluh darah, manfaat yang baik akan tercapai dalam waktu 30 menit sesudah pengopresan (Bachtiar, 2015).

Jahe (Zingiber officinale) adalah tanaman obat berupa tumbuhan rumpun berbatang semu. Jahe berasal dari Asia, yang tersebar dari India sampai Cina. kedua negara inilah yang pertama kali memanfaatkan jahe, terutama sebagai bahan minuman, bumbu masak dan obat (Hernani \& Winarti, 2010). 
PENERAPAN TEKNIK KOMPRES HANGAT JAHE TERHADAP PENGENDALIAN LEVEL NYERI DENGAN KASUS RHEUMATOID ARTRITIS

Banyaknya kasus rheumatoid arthritis yang mengeluh rasa nyeri baik serta efek samping dari penggunaan obat sintesis serta tingginya komponen kimia jahe seperti gingerol yang mampu memberi efek farmakologi dan fisiologi seperti antiinflamasi dan analgesik. Olehnya itu peneliti tertarik untuk menerapkan kompres jahe sebagai salah satu intervensi non farmakologi yang dapat dilakukan oleh pasien secara mandiri murah serta mudah dilakukan untuk menurunkan nyeri.

\section{GAMBARAN KASUS}

Ny. H, lahir di Bone, umur 78 Tahun, jenis Kelamin perempuan, pendidikan terakhir SMA, golongan darah B, Islam, menikah, tinggi badan $156 \mathrm{~cm}$, berat badan $48 \mathrm{Kg}$, penampilan rapi, dan beralamat di Dusun Patirobajo Kelurahan Kasiguncu. Keluhan utama nyeri pada bagian lutut, nyeri bertambah saat beraktivitas, nyeri dirasakan hilang timbul seperti tertusuk, nyeri dirasakan pada bagian lutut, skala nyeri 6 , nyeri dirasakan selama 20 menit.

$$
\text { Hasil pemeriksaan fisik }
$$

keadaan umum baik, kesadaran composmentis, GCS E:4, M:6, V:5, Tekanan darah 170/80 mmHg, nadi $68 \mathrm{x} / \mathrm{menit}$, respirasi $16 \mathrm{x} / \mathrm{menit}$, suhu 0

36,2 C. Pemeriksaan fisik dilakukan secara head to toe mulai dari bentuk kepala brachiocepalus, tidak terdapat trauma pada kepala, tidak terdapat luka dan lesi pada kepala, tidak terdapat benjolan, tidak ada nyeri tekan, mata simetris kiri dan kanan, tidak terdapat strabismus, penglihatan kurang baik, pandangan kabur, dan tidak ada nyeri tekan. Telinga simetris kiri dan kanan, tidak terdapat serumen, pendengaran baik, tidak terdapat nyeri tekan. Hidung simetris kiri dan kanan, tidak terdapat sekret, masih mampu membedakan bau, tidak terdapat nyeri tekan, leher tidak

terdapat kekakuan, tidak terdapat benjolan/massa, tidak ada pembesaran kelenjar tyroid, dan tidak ada nyeri tekan. Dada simetris kiri dan kanan, tidak terlihat penggunaan otot bantu pernapasan, bentuk dada normal chest, pada perkusi paru suara napas sonor, dan pada auskultasi suara nafas vesikuler, tidak terdapat nyeri tekan. Abdomen tampak tidak ada lesi, tidak ada benjolan, bising usus 10x/menit, perkusi terdengar tympani, dan tidak terdapat nyeri tekan. Ekstremitas atas dan bawah kedua kaki dan tangan Ny. H tampak sejajar dan sama besar, kemampuan mengubah posisi baik, pergerakan kedua tangan dan kaki baik, kekuatan otot baik, tetapi lutut bagian kiri terasa nyeri dan kesemutan, nyeri dirasakan akibat beraktivitas, nyeri dirasakan hilang timbul seperti tertusuk, nyeri dirasakan pada bagian persendian lutut, skala nyeri 6 , dan durasinya 20 menit. Genitalia BAK 5-6 kali sehari, BAB 2 kali sehari, konsistensi lunak, warna kuning kecoklatan, tidak sakit saat BAK dan BAB, bau urin khas amoniak. Sistem persyarafan tidak ada cedera kepala, tidak ada 
PENERAPAN TEKNIK KOMPRES HANGAT JAHE TERHADAP PENGENDALIAN LEVEL NYERI DENGAN KASUS RHEUMATOID ARTRITIS

peningkatan TIK, dan tidak memiliki riwayat kejang, Sistem pengecapan baik, sistem penciuman baik. Data penunjang seperti GDS: $83 \mathrm{mg} / \mathrm{dl}$, kolestrol: 148 mg/dl, asam urat: 3,6 mg/dl, HB: 6,5. Ny. H mengkonsumsi obat natrium diklofenak, methylprednisolon, dan amlodipin.

\section{METODE PENELITIAN}

Metode dalam penelitian ini yaitu studi kasus pada penderita rheumatoid arthritis dengan tindakan asuhan keperawatan kompres hangat jahe untuk mengendalikan level nyeri. Penelitian ini dilaksanakan di rumah Ny. H pada tanggal 20 - 29 Juni 2018. Subyek dalam studi kasus ini adalah penderita rheumatoid arthritis. Tindakan asuhan keperawatan yang diberikan adalah kompres hangat jahe untuk mengendalikan level nyeri.

Cara pembuatan kompres hangat rebusan jahe ini dengan cara mencuci 5 rimpang jahe $( \pm 100$ gram $)$ dan iris tipistipis) setelah itu masukkan irisan jahe ke dalam 1 liter air, rebus irisan jahe sampai air mendidih (1000 cc), tuang rebusan jahe ke dalam baskom, tunggu hingga suhu rebusan jahe menjadi hangat tanpa campuran air dingin $(400 \mathrm{cc})$.

$$
\text { Cara pemberian kompres }
$$

rebusan jahe yaitu dengan cara memasukkan washlap atau handuk kecil ke dalam baskom rebusan jahe hangat. Peras washlap atau handuk kecil sampai lembab dan kemudian tempelkan pada area yang sakit hingga kehangatan washlap atau handuk kecil terasa berkurang. Ulangi langkah tersebut \pm 15 menit.

Teknik pengumpulan data dalam studi kasus ini meliputi wawancara, pemeriksaan fisik, observasi dan studi dokumentasi. Data yang telah terkumpul dilakukan analisis untuk menetapkan masalah keperawatan yang dialami klien, melakukan penerapan kompres hangat jahe serta mengevaluasi keefektifan tindakan yang telah dilakukan dalam menurunkan nyeri. Penyajian data dilakukan dalam bentuk narasi.

\section{HASIL}

Pengkajian yang dilakukan ditemukan masalah keperawatan yang terjadi yaitu nyeri akut. Nyeri akut, data yang berhubungan adalah agen cedera biologis (kesemutan dan rasa ngilu pada persendian) yang ditandai dengan mengeluh sering nyeri dan kesemutan pada bagian lutut sebelah kanan, nyeri bertambah jika beraktivitas, TD: $170 / 80 \mathrm{mmHg}, \mathrm{N}$ : 68x/menit, R: 16x/menit, $\mathrm{S} 36,2^{0} \mathrm{C}$, skala nyeri 6 , terdapat nyeri tekan pada bagian lutut.

\section{PEMBAHASAN}

Keluhan utama yang dirasakan oleh $\mathrm{Ny}$. H yaitu nyeri pada bagian lutut, nyeri bertambah saat beraktivitas, nyeri dirasakan hilang timbul seperti tertusuk, nyeri dirasakan pada bagian lutut, skala nyeri 6 , nyeri dirasakan selama 20 menit. Riwayat 
PENERAPAN TEKNIK KOMPRES HANGAT JAHE TERHADAP PENGENDALIAN LEVEL NYERI DENGAN KASUS RHEUMATOID ARTRITIS

penyakit dahulu yag diderita oleh klien adalah hipertensi dan rheumatoid arthritis, dan klien belum pernah dirawat di rumah sakit.

Pemeriksaan fisik yang didapatkan pada Ny.H yaitu keadaan umum baik, kesadaran composmentis, tekanan darah 170/80 $\mathrm{mmHg}$, nadi $68 \mathrm{x} / \mathrm{menit}$, respirasi 0

16x/menit, suhu badan $36,2 \mathrm{C}$, skala nyeri

6 , terdapat nyeri tekan pada bagian lutut. Pada bagian ekstremitas atas dan bawah kedua kaki dan tangan $\mathrm{Ny}$. H tampak sama besar dan sejajar, kekuatan otot baik, kemampuan mengubah posisi baik, pergerakan kedua tangan dan kaki baik, namun lutut kiri terasa nyeri dan kesemutan.

Diagnosa keperawatan yang sering muncul pada klien yang menderita rheumatoid arthritis adalah nyeri akut, hambatan mobilitas fisik, ansietas, gangguan citra tubuh, resiko jatuh, defisit perawatan diri (mandi), dan defisit perawatan diri eliminasi (Wilkinson, 2014). Berdasarkan hasil pengkajian yang dilakukan penulis, didapatkan masalah keperawatan prioritas yaitu nyeri akut ditandai dengan data subjektif $\mathrm{Ny}$. H mengeluh sering nyeri dan kesemutan pada bagian lutut sebelah kanan, nyeri bertambah jika beraktivitas, data objektif yang diperoleh yaitu tekanan darah 170/80

mmHg, nadi 68x/menit, respirasi 0 16x/menit, suhu badan $36,2 \mathrm{C}$, skala nyeri 6 , dan terdapat nyeri tekan pada bagian lutut. Berdasarkan diagnosa yang didapatkan pada Ny.H sejalan dengan teori yang ada namun penulis hanya berfokus pada satu diagnosa prioritas yang diterapkan pada pasien yaitu nyeri akut.

Nyeri sendi pasien rheumatoid arthritis sebelum diberikan kompres hangat jahe dapat membantu dalam partisipasi perawatan diri. Hasil penelitian yang dilakukan menunjukkan bahwa semakin bertambah usia seseorang akan mengalami beberapa perubahan dalam dalam diri mereka secara fisiologis dan psikologis, diantara perubahan fisiologis tersebut adalah perubahan pada mekanisme kardiovaskuler sehingga dapat menyebabkan terjadinya penyakit degeneratif seperti tekanan darah tinggi (Karepowan, Wowor, \& Katuuk, 2018). Intensitas nyeri sendi rheumatoid lansia sebelum diberikan kompres hangat jahe bervariasi karena sifat nyeri adalah subyektif.

Dari hasil penelitian yang dilakukan pada Ny.H sebelum dilakukan tindakan kompres hangat jahe, klien mengatakan bahwa ia merasakan nyeri pada bagian lutut sebelah kiri, durasi dari nyeri tersebut berlangsung selama 20 menit dan biasanya nyeri bertambah saat klien beraktivitas. Untuk itu peneliti menerapkan teknik nonfarmakologis yaitu kompres hangat jahe. Kompres jahe ini merupakan pengobatan tradisional atau terapi komplementer untuk mengurangi nyeri rheumatoid arthritis. 
PENERAPAN TEKNIK KOMPRES HANGAT JAHE TERHADAP PENGENDALIAN LEVEL NYERI DENGAN KASUS RHEUMATOID ARTRITIS

Kandungan enzim siklo-oksigenasi pada air kompres jahe hangat berkhasiat mengurangi peradangan pada penderita rheumatoid arthritis (Rahmawati, 2016), selain itu jahe juga memiliki efek farmakologis yaitu rasa panas dan pedas, dimana rasa panas ini dapat meredakan rasa nyeri, kaku, dan spasme otot atau terjadinya vasodilatasi pembuluh darah, manfaat yang maksimal akan dicapai dalam waktu 20 menit sesudah aplikasi panas. Efek panas pada jahe inilah yang dapat meredakan nyeri, kaku dan spasme otot pada rheumatoid arthritis. Jahe juga banyak mempunyai kandungan seperti minyak atsiri, oleoresin dan pati sehingga dapat untuk menyembuhkan tubuh (Pairul, Susianti, \& Nasution, 2017), selain itu jahe banyak mempunyai khasiat seperti antihelmintik (Ramadhani, 2016).

Hasil penelitian yang dilakukan di Dusun Patirobajo di kelurahan Kasiguncu pada Ny. H setelah dilakukan pemberian terapi kompres hangat jahe selama 1 minggu dengan 3 kali pemberian terapi kompres hangat jahe menunjukkan perubahan yang signifikan, Ny. $\mathrm{H}$ mengatakan sebelum diberikan kompres hangat jahe klien merasakan nyeri dengan skala nyeri 6 , tetapi setelah pemberian 3 kali terapi kompres hangat klien merasakan nyerinya sudah tidak ada dan dapat berjalan secara normal. Sebelumnya Ny. H jarang atau bahkan belum pernah melakukan terapi pengobatan nyeri sendi rhematoid dengan menggunakan kompres hangat jahe, Ny. $\mathrm{H}$ hanya mengandalkan obat-obatan medis seperti natrium diklofenak, sehingga ada kalanya Ny. H tidak mengkonsumsi obatobatan medis tersebut karena merasa bosan dan malas untuk terus mengkonsumsi obat tersebut. Setelah Ny. H diberikan kompres hangat jahe intensitas nyeri $\mathrm{Ny}$. $\mathrm{H}$ menjadi menurun karena efek kompres hangat jahe dapat merelaksasikan otot, menghambat terjadinya inflamasi, memberi perasaan

nyaman, merangsang pengeluaran endhorpins dan antirematik (Margono, 2016).

Hal ini didukung oleh penelitian Mantiri (2013), melihat perbandingan efek analgesik perasan rimpang jahe dengan aspirin dosis terapi, adapun hasilnya tidak terdapat perbedaan yang bermakna antara kelompok perlakuan perasan rimpang jahe dosis I, namun terdapat perbedaan yang signifikan antara pemberian aspirin dengan perasan jahe dosis II dan III, dan tidak terdapat perbedaan antara pemberian perasan rimpang jahe dosis II dan III, jadi dosis maksimal perasan rimpang jahe adalah $8 \mathrm{mg}$ (Mantiri, Awaloei, \& Posangi, 2013). Adapun efek analgesik kompres hangat jahe berhubungan dengan unsurunsur yang terkandung dalam jahe.

Senyawa-senyawa gingerol, shogaol, zingerole (heptanoids dan derivat) terutama paradol diketahui dapat menghambat siklooksigenasi sehingga terjadi penurunan pembentukan atau 
PENERAPAN TEKNIK KOMPRES HANGAT JAHE TERHADAP PENGENDALIAN LEVEL NYERI DENGAN KASUS RHEUMATOID ARTRITIS

biosintesis dari prostaglandin yang menyebabkan berkurangnya rasa nyeri (Hernani \& Winarti, 2010).

Penelitian lain Susanti (2014), tentang pengaruh kompres jahe terhadap intensitas nyeri penderita reumathoid arthritis sebanyak 20 orang lansia yang menderita rheumathoid arthritis dengan rata-rata nyeri sebelum kompres jahe (pre-test) yaitu 3,80 dengan standar deviasi 1,005 dan rata-rata nyeri setelah kompres jahe (post-test) yaitu 2,80 dengan standar deviasi 1,005 berdasarkan uji Wilcoxon didapatkan nilai $\mathrm{p}<0,001(<0,05)$, berarti ada pengaruh yang signifikan terhadap penurunan intensitas nyeri rheumatoid arthritis pada lansia (Susanti, 2014).

Berdasarkan data penelitian yang telah diperoleh, kompres jahe terlihat memiliki pengaruh dalam mengurangi intensitas nyeri rheumathoid arthritis dimana $\mathrm{Ny} . \mathrm{H}$ mengalami penurunan intensitas nyeri setelah perlakuan kompres jahe selama 20 menit.

\section{DAFTAR PUSTAKA}

Bachtiar, A. (2015). Pengaruh Ekstrak Jahe (Zingiber Officinale) terhadap Tanda dan Gejala Osteoartritis pada Pasien Rawat Jalan di Puskesmas Pandan Wangi Kota Malang.

Fakultas Ilmu Keperawatan, Universitas Indonesia, Depok. Departemen Kesehatan R.I. (2008). Riset

Kesehatan Dasar Riskesdas 2007, Laporan Nasional 2007. Retrieved from Badan Penelitian dan

Pengembangan Kesehatan Kementerian Kesehatan R.I
Jadi dapat ditarik kesimpulan bahwa pemberian terapi kompres hangat jahe dengan 3 kali pemberian pada pagi hari selama 1 minggu dalam waktu 20 menit dapat menurunkan nyeri lutut yang dirasakan Ny. H karena jahe memiliki kandungan enzim siklo-oksigenasi dan efek panas yang berfungsi sebagai antiinflamasi dan dapat menurunkan sensasi nyeri.

\section{PENUTUP}

Dalam memberikan asuhan keperawatan semua masalah bisa teratasi salah satunya masalah nyeri. Pemberian terapi kompres hangat jahe dengan 3 kali pemberian selama 1 minggu dapat menurunkan nyeri lutut yang dirasakan klien. Skala nyeri sebelum diberikan kompres hangat jahe pada pasien rheumatoid arthritis yaitu dengan skala nyeri 6 , setelah diberikan kompres hangat jahe menjadi skala 3 .

website:

http://terbitan.litbang.depkes.go.id/ penerbitan/index.php/lpb/catalog/d ownload/22/22/29-2

He, W., Goodkind, D., \& Kowal, P. (2016). An Aging World: 2015. https://doi.org/10.13140/rg.2.1.108 8.9362

Hernani, \& Winarti, C. (2010). Kandungan Bahan Aktif Jahe dan Pemanfaatnya Dalam Bidang Kesehatan. Jakarta: Balai Besar Penelitian dan Pengembangan Pascapanen Pertanian. 
Karepowan, S. R., Wowor, M., \& Katuuk, M. (2018). Hubungan Kemunduran Fisiologis dengan Tingkat Stres pada Lanjut Usia di Puskesmas Kakaskasen Kecamatan Tomohon Utara. e-Journal Keperawatan, 6(1), 7.

Kementerian Kesehatan R.I. (2013). Riset

Kesehatan Dasar Riskesdas 2013. Retrieved from Badan Penelitian dan Pengembangan Kesehatan Kementerian Kesehatan R.I website:

http://www.depkes.go.id/resources/ download/general/Hasil\%20Riskes das\%202013.pdf

Mantiri, N. C., Awaloei, H., \& Posangi, J. (2013). Perbandingan Efek Analgetik Perasan Rimpang Jahe (Zingiber officinale var. rubrum Thelaide) dengan Aspirin Dosis Terapi pada mencit (Mus musculus). Jurnal E-Biomedik (EBM), 1(1), 518-523.

Margono. (2016). Pengaruh Terapi Zinger Officinale terhadap Intensitas Nyeri Low Back Pain di Posyandu Margomulyo Desa Ngrancah Kecamatan Grabag. Jurnal Keperawatan Muhammadiyah, $1(1), 58-62$.

Pairul, P. P. B., Susianti, \& Nasution, S. H. (2017). Jahe (Zingiber Officinale) Sebagai Anti Ulserogenik. Medula, 7(5), 42-46.

Puskesmas Mapane. (2017). Laporan Rutin Puskesmas Mapane. Mapane: Puskesmas Mapane.

Rahmawati, I. (2016). Pengaruh Pemberian Minum Jahe Hangat dengan Intensitas Nyeri pada Persalinan Kala I di Rsia Kumalasiwi Kabupaten Jepara. Jurnal
Kebidanan Universitas Muhammadiyah Semarang, 5(2), 7.

Ramadhani, A. K. (2016). Efek Antelmintik Ekstrak Etanol Rimpang Jahe Merah (Zingiber officinale Roscoe var. rubrum) terhadap Cacing Ascaris suum Goeze secara in Vitro. Universitas Sebelas Maret, Surakarta.

Singh, J. A., Saag, K. G., Bridges, S. L., Akl, E. A., Bannuru, R. R., Sullivan, M. C., ... McAlindon, T. (2016). 2015 American College of Rheumatology Guideline for the Treatment of Rheumatoid Arthritis: ACR RA Treatment Recommendations. Arthritis Care \& Research, 68(1), 1-25. https://doi.org/10.1002/acr.22783

Smith, H. R. (2018, June 5). Rheumatoid Arthritis: Practice Essentials, Background, Pathophysiology. Retrieved May 19, 2019, from https://emedicine.medscape.com/art icle/331715-overview\#a5

Susanti, D. (2014). Pengaruh Kompres Hangat Jahe terhadap Intensitas Skala Nyeri Osteoarthritis pada Lansia di Panti Sosial Tresna Werdha Kasih Sayang Ibu Batu Sungkar 2014. Fakultas Kesehatan dan MIPA Universitas Muhammadiyah Sumatera Barat, Padang.

Wilkinson, J. M. (2014). Pearson Nursing Diagnosis Handbook with NIC Interventions and NOC Outcomes. Boston: Pearson. 